\title{
20. Mutations in Einkorn Wheat Induced by X-rays. I. Chlorina Mutants*)
}

\author{
By Tarô FuJII \\ National Institute of Genetics, Misima, Japan \\ (Comm. by H. Kinara, M.J.A., Feb. 18, 1955)
}

Chlorina mutants, besides often occurring spontaneously, are induced frequently by ionizing radiation. Some of them show Mendelian and others plasmic inheritance. Comprehensive studies in this field were carried out by Gustafsson and his co-workers. Gustafsson (1940) found various chlorophyll mutants such as albina, xantha, alboviridis, viridis, etc., induced by X-irradiation of dry dormant seeds of barley. Holm (1954) investigated the physiological properties and genetics of chlorophyll mutations in barley produced by means of X-irradiation. D'Amato (1950) pointed out that chlorophyll mutations could be produced with chemical compounds, such as acriflavine, acridine orange, etc. According to Matsumura and Fujii (1953) chlorophyll mutants amounted about to $70 \%$ of all mutations in the $\mathrm{X}_{2}$-generation of $\mathrm{X}$-irradiated Einkorn wheat.

Cytological, morphological and biochemical investigations of differences between the normals and the mutants might contribute to our knowledge of the mechanism of mutation.

The author reports in this paper the results of his study of the morphological and biochemical differences between the normals and the chlorina mutants in Einkorn wheat (Triticum monococcum $\mathrm{L}$. var. flavescens Körn.). The mutants appeared in the $\mathrm{X}_{2}$-generation from seeds treated with 5,400 $r$ dose, at $180 \mathrm{KVP}, 3 \mathrm{~mA}$ tube current, $13 \mathrm{~cm}$ target distance, without filter. Exposed to X-rays were dry dormant seeds in 1951. The experiments were carried out in the National Institute of Genetics, Misima (cf. Fujii, 1954).

Morphological Observations. Matsumura and Fujii (1953) obtained several recessive chlorophyll mutants in Einkorn wheat, such as albina, white stripe, viridis, etc., besides the chlorina mutants. The majority of these mutants had a high mortality or apparently recovered the normal green coloring in the middle stages of growth, whereas only the chlorina mutants remained chlorina from seedling stage to maturity.

5 chlorina plants appeared among 7 plants in the $\mathrm{X}_{2}$-generation. The mutants were crossed reciprocally with normal $T$. monococcum, T. aegilopoides Bal. var. boeoticum (Boiss.) Perc. and with various

*) Contributions from the National Institute of Geretics, Japan, No. 100. 
other mutants. The $\mathrm{F}_{1}$ plants were normal green and the $\mathrm{F}_{2}$ segregated in the Mendelian monohybrid ratio. The chlorina mutation, therefore, is simply recessive.

Observation of chromosome conjugation was carried out in the $\mathrm{X}_{1^{-}}$and $\mathrm{X}_{4}$-generations in pollen mother cells. Smear technique with aceto-carmine was used. Chromosome conjugation of the mutants was always normal, and $7_{\text {II }}$ were formed at metaphase. Nevertheless, plant height, viability and fertility of the mutants were a little inferior to those of the normals, namely, plant height was about $25 \mathrm{~cm}$ lower, fertility about 15\% lower and the time of heading and ripening was delayed about 10 days in comparison with the normals (Table I).

Table I. Morphological differences between normal green and chlorina mutants

\begin{tabular}{|c|c|c|c|c|c|c|c|}
\hline & \multirow{3}{*}{$\begin{array}{c}\text { Chromosome } \\
\text { conjugation } \\
(1951,1954)\end{array}$} & \multirow{2}{*}{\multicolumn{2}{|c|}{$\begin{array}{l}\text { Plant height }(\mathrm{cm}) \\
(1953)\end{array}$}} & \multirow{3}{*}{ Fertility $(\stackrel{※}{\%})$} & \multicolumn{3}{|c|}{ Stomata (1954) } \\
\hline & & & & & \multirow{2}{*}{$\begin{array}{l}\text { Length } \\
(\mathrm{mm})\end{array}$} & \multirow{2}{*}{$\begin{array}{l}\text { Width } \\
(\mathrm{mm})\end{array}$} & \multirow{2}{*}{$\begin{array}{l}\text { Distri- } \\
\text { bution } \\
\text { density }\end{array}$} \\
\hline & & Mean & Variation & & & & \\
\hline Normal & 7 II & 140.5 & $127-156$ & $\begin{array}{|rr|}1952 & 93.19 \\
1953 & 80.59 \\
1954 & \mathrm{~s} 84.36\end{array}$ & 0.0374 & 0.0219 & 10.03 \\
\hline Mutant & $7 \mathrm{II}$ & 114.9 & 93-1.33 & \begin{tabular}{rr|}
1952 & 75.66 \\
1953 & 76.88 \\
1954 & $\mathrm{~s} 69.96$
\end{tabular} & 0.0405 & 0.0228 & 11.18 \\
\hline & & & & Difference & $-0.0031^{* *}$ & $-0.0009^{*)}$ & -1.15 \\
\hline
\end{tabular}

※ s-mark means that the ears were bagged; average fertility of 5 individuals in 1952 and 1953.

*) Exceeds the $5 \%$ level of significance.

** Exceeds the 1\% level of significance.

Size and number of stomata were observed in 1954. The flag leaves were collected from ten normal individuals and ten plants of the mutants. In every leaf the length and width of 20 stomata were measured with ocular micrometer and their distribution density was examined in 20 microscopical fields. ${ }^{1)}$ The results were examined by means of $t$-test. There was a statistically significant difference in the size of stomata between the normals and the mutants, but none was found in the distribution density of stomata (Table I).

Chlorophyll Content. Chlorina mutants were of an olive green, while the coloring of the normals was grass green according to the Color Standard. Gustafsson (1940), in his extensive investigation, classified his chlorophyll mutants in barley into eleven various

1) According to private communication of Dr. D. C. Cooper to Dr. S. Matsumura some differences in shape and distribution density of stomata were found between the normals and the chlorophyll mutants, such as variegated and striped. 
groups and sub-divided most of them into smaller units. It is assumed from a morphological and physiological comparison of severals character that my chlorina mutants correspond to Gustafsson's chlorina in his viridis group.

The investigation of differences in chlorophyll content between the normals and the mutants was carried out in the middle of May in 1954, according to Asami's method (1952). 5 grams of fresh leaves (only flag leaves) were collected from several plants and extracted in darkness and at low temperature for about $24 \mathrm{hrs}$. with 60 ce fluid composed of 3 parts methanol and 1 part aceton. Extinction $(E)$ of both extracts of the normals and the mutants was measured at the wave length of $4,230 \AA$ with the Beckmanspectrophotometer. $0.5 \mathrm{cc}$ of these extracts were used for separation of the chlorophyll components into $a$ and $b$ by paper chromatographic method, and each of them was re-extracted from the filter paper with $5 \mathrm{cc}$ of ethanol. The amounts of chlorophyll a and $b$ were estimated by measuring the $E$-values at $4,230 \AA$ and $4,500 \AA$ respectively.

The chlorophyll amount of the mutants was about 1/2 compared with that of the normals, namely, the ratio of extinction of extract (chlorophyll $\mathrm{a}+\mathrm{b}$ ) in the normals and the mutants was 184:100, that of chlorophyll a $364: 204$ and that of chlorophyll b 156:79, respectively (Table II). Similar results were also obtained from the extract of dry leaves in the middle of September.

Table II. Chlorophyll amounts in the normals and the mutants

\begin{tabular}{c|c|cc|c}
\hline & \multicolumn{3}{|c|}{ Extinction of fresh leaves } & \multicolumn{2}{c}{$\begin{array}{c}\text { Extinction of the extract } \\
\text { of dry leaves }(4,230 \AA)\end{array}$} \\
\cline { 2 - 5 } & Extract $(4,230 \AA)$ & a $(4,230 \AA)$ & b $(4,500 \AA)$ & 160 \\
Normal & 184 & 364 & 156 & 72 \\
\hline
\end{tabular}

Activity of Cytochrome Oxidase. Activity of cytochrome oxidase was measured with Warburg constant volume respirometer (manometer) according to Umbreit et al. (1951). Only flag leaves (3 grams) were collected at random from several individuals in the middle of June in 1954 (about 2 weeks after heading) and these leaves were homogenized with 4.5 cc of Sörensen phosphate buffer $(\mathrm{pH} \mathrm{7.4)}$ and 10.5 cc of $0.25 \mathrm{Mol}$. sucrose, at a low temperature $\left(c a .0^{\circ} \mathrm{C}\right)$ by a tissue homogenizer. These mixtures were fractionated to the supernatant and the sediment subjected to a centrifuge at 2,000 rounds per minute during 5 minutes.

Manometric measurements were carried out in these super- 
natants with the Warburg apparatus, cytochrome $\mathrm{C}$ having been added as substrate. The cytochrome $\mathrm{C}$ was obtained from an extract of the heart muscle of cattle. The reaction components were placed in a manometric flask in the following amounts:

\begin{tabular}{|c|c|c|}
\hline \multirow{6}{*}{ Flask: } & $5 \%$ supernatant & $0.5 \mathrm{cc}$ \\
\hline & $2.4 \times 10^{-4}$ Mol. cytochrome C & $0.5 \mathrm{cc}$ \\
\hline & $4 \times 10^{-3} \mathrm{Mol} . \mathrm{AlCl}_{3}$ & $0.3 \mathrm{cc}$ \\
\hline & $0.114 \mathrm{Mol}$. Na-ascorbate, $\mathrm{pH} 7.0$ & $0.3 \mathrm{cc}$ \\
\hline & Sörensen phosphate buffer, $\mathrm{pH} 7.4$ & $0.5 \mathrm{cc}$ \\
\hline & $\mathrm{H}_{2} \mathrm{O}$ & $0.9 \mathrm{cc}$ \\
\hline Center well: & $2 \mathrm{~N} \mathrm{NaOH}$ & $0.2 \mathrm{cc}$ \\
\hline
\end{tabular}

In Normal+KCN lot, $0.5 \mathrm{cc}$ of $10^{-4} \mathrm{Mol}$. KCN was used as an inhibitor to cytochrome $\mathrm{C}$ and $0.4 \mathrm{cc}$ of $\mathrm{H}_{2} \mathrm{O}$, instead of the $0.9 \mathrm{cc}$ of $\mathrm{H}_{2} \mathrm{O}$.

Table III. Manometric rates of the normals and the mutants (ml)

\begin{tabular}{c|c|c|c|c|c|c}
\hline Minutes & 10 & 20 & 30 & 40 & 50 & 60 \\
\hline Lot & & & & & & \\
\hline Mutant*) & 0.962 & 1.925 & 2.743 & 3.572 & 4.413 & 5.214 \\
Normal+KCN & 0.429 & 0.933 & 1.413 & 1.792 & 2.259 & 2.609 \\
\hline
\end{tabular}

*) These data show the average rates of two flasks of the same supernatant.

The manometric rates are given as the maximum oxygen consumption, in micro-liters, obtained in any 10 minutes period. These manometric rates reveal the activity of cytochrome oxidase.

Manometric rates were 10, 30, and 60 minutes after treatment $0.962,2.743$, and $5.214 \mathrm{ml}$ in the normals and $0.429,1.413$, and $2.609 \mathrm{ml}$ in the mutants, respectively. Further these rates in Normal $+\mathrm{KCN}$ lot, where KCN was used as an inhibitor to cytochrome $\mathrm{C}$, were $0.414,1.160$, and $2.072 \mathrm{ml}$ respectively (Table III). Namely, manometric rates of the mutants were about half of those of the normals and similar to those in the Normal + KCN lot. These results were in good accord with those of a previous experiment (1953) carried out under similar conditions.

Discussion. According to Mikaelsen and Halversen (1954) the respiration rate decreases markedly after the germination of irradiated dry dormant seeds of barley, treated with X-rays at 5,000-15,000 $r$, compared with that of the non-irradiated seeds, and the relation between dosage and respiration rate shows a sigmoid curve. Barron (1952) pointed out that the mutation induced by ionizing radiations arises directly and indirectly. In the former case the cell components may obviously be affected by direct collision with the ionizing radiation. In the latter they will be affected by the product of ionization of water and oxygen, which is present in the tissue. and these products and their oxidation will inhibit the activity 
of the enzyme system. For example, reduced cytochrome $\mathrm{C}$ is oxidized by irradiation with X-rays and the rate of oxidation is about 20, 45, and $95 \%$ at the dosage of 2,000, 5,000, and 10,000 r respectively. In our experiments with 5,400 $r$ dose the activity of cytochrome oxidase in the chlorina mutants was about $50 \%$ of that found in the normals (Table III). Our results are, therefore, in good accord with those of Barron. DuBuy et al. (1950) reported that the chloroplasts of higher plants derive from the mitochondrial elements of the cell and that cytochrome oxidase is present in the mitochondria. As shown in Tables II and III, our experiments also show that the chlorophyll amount of the mutants is only about half of that of the normals, in concord with the activity rate of cytochrome oxidase. It is supposed that the chlorophyll might be controlled by the activity of cytochrome oxidase. The relation between the chlorophyll amount and the activity of cytochrome oxidase awaits further investigation. Differences in morphological characters and viability between the normals and the mutants must be mostly due to a reduction of the activity of cytochrome oxidase.

Acknowledgements. The author begs to express his indebtedness to Dr. Seiji Matsumura, National Institute of Genetics, for his guidance and encouragement. Also, he is greatly indebted to Mr. Saburo Nawa and Mr. Bungo Sakaguchi for their kind advices and assistances in biochemical techniques.

\section{References}

Asami, M.,: On the paper chromatography of the leaf pigments I, Bot. Mag., Tokyo, 65, 217-223 (1952).

Barron, E. S. G.,: The effect of ionizing radiations on some system of biological importance, Symp. Radiobiol., New York, 216-240 (1952).

D'Amato, F.,: Chlorophyll mutations in barley induced by acridine derivatives, Caryologia, 3, 211-220 (1950).

DuBuy, B. G., Woods, M. W., and Lackey, M. D.,: Enzymatic activities of isolated normal and mutant mitochondria and plastids of higher plants, Science, 111, 572-574 (1950).

Fujii, T.,: Studies in chlorina mutants of Einkorn wheat induced by X-rays, Jap. Jour. Genet. (in Jap.), 29, 153 (1954).

Gustafsson, A.,: The mutation system of the chlorophyll apparatus, Lund Univ. Årsskrift. N.F., 2, 1-40 (1940).

Holm, G.,: Chlorophyll mutations in barley, Acta Agric., Scandinavia, 4, 457-471 (1954).

Matsumura, S., and Fujii, T.,: X-ray induced mutants in Einkorn wheat (in Jap.), Jap. Jour. Genet., 28, 175 (1958).

Mikaelsen, D., and Halversen, H.,: Experiments on the respiration of X-irradiated barley seeds, Physiol. Plantarum, 6, 873-879 (1953).

Umbreit, W. W., Burris, R. H., and Stauffer, J. F.,: Manometric techniques and tissue metabolism, Minneapolis (1951). 